\title{
INSTITUIÇÕES PÚBLICAS: ANÁLISE E REFLEXÃO DAS DIFERENTES REALIDADES DO PROFESSOR
}

\author{
INSTITUCIONES PÚBLICAS: ANÁLISIS Y REFLEXIÓN DE
}

DIFERENTES REALIDADES DEL PROFESOR

\section{PUBLIC INSTITUTIONS: ANALYSIS AND REFLECTION OF}

\section{DIFFERENT REALITIES OF THE TEACHER}

\author{
Carla SilvaTormam ${ }^{1}$ \\ Vanderleia Lucia Dick Conrad2 \\ Paula Trindade da Silva Selbach3
}

\begin{abstract}
Resumo
Este artigo tem como objetivo realizar reflexões acerca dos desafios da profissão docente na sociedade contemporânea, com o intuito de evidenciar a necessidade e a importância da formação continuada e da valorização do professor. Para isso, analisar-se-á duas instituições públicas, porém, com realidades e contextos completamente distintos e, a partir delas, comparar os impactos nos processos de ensino e de aprendizagem. Os resultados obtidos foram significativos e esclarecedores, capazes de apontar aspectos imprescindíveis para o êxito da profissão docente, de forma a delinear caminhos possíveis para uma educação de qualidade.

Palavras-chave: Profissão Docente. Valorização do Professor. Educação de Qualidade.
\end{abstract}

Este artículo tiene como objetivo reflexionar sobre los desafíos de la profesión docente en la sociedad contemporánea, con el fin de resaltar la necesidad e importancia de la educación continua y la valoración del profesorado. Para ello, se analizarán dos instituciones públicas, sin embargo, con realidades y contextos completamente diferentes y, a partir de ellas, comparar los impactos en los procesos de enseñanza y aprendizaje. Los resultados obtenidos fueron significativos y esclarecedores, capaces de señalar aspectos esenciales para el éxito de la profesión docente, con el fin de delinear posibles caminos para una educación de calidad.

Palabras clave: Profesión docente. Apreciación del maestro. Educación de calidad.

\footnotetext{
Abstract

This article aims to reflect on the challenges of the teaching profession in contemporary society, in order to highlight the need and importance of continuing education and teacher appreciation. For this, two public institutions will be analyzed, however, with completely different realities and contexts and, from them, compare

11 Aluna do Programa de Pós-Graduação em Educação da Universidade Federal do Pampa - UNIPAMPA / Campus Jaguarão. carlatormam@gmail.com

2 Aluna do Programa de Pós-Graduação em Educação da Universidade Federal do Pampa - UNIPAMPA/ Campus Jaguarão. conradvanderleia@gmail.com

3 Professora permanente do Programa de Pós-Graduação em Educação da Universidade Federal do Pampa UNIPAMPA/ Campus Jaguarão. paulaselbach@unipampa.edu.br.
} 
the impacts on the teaching and learning processes. The results obtained were significant and enlightening, capable of pointing out essential aspects for the success of the teaching profession, in order to outline possible paths for quality education.

Keywords: Teaching profession. Teacher Appreciation. Quality education.

\section{Introdução}

Este artigo busca criar um contraponto sobre as diferentes realidades encontradaspelos professores em duas escolas públicas, evidenciando a importância da formação continuada, e consequentemente sua valorização enquanto profissional.

Apresentamos no próximo capítulo um comparativo entre o Colégio Militar de Porto Alegre, instituição pública, e a de uma escola também pública do município de Jaguarão, demonstrando o universo de diferenças que separam as realidades destas duas instituições.

Por fim, destacamos a importância da formação continuada na qualidade e valorização do profissional docente, abordando questões relevantes que levam-nos a refletir sobre a prática do professor e a importância da formação continuada.

\section{O contraponto das realidades das Escolas Públicas}

\subsection{A realidade do Colégio Militar de Porto Alegre}

Os Colégios Militares, assim como outros espaços educacionais, possui um regimento próprio, visto que são organizações militares (OM), que funcionam como estabelecimentos de ensino de educação básica, integram o SCMB, que é um dos subsistemas do Sistema de Ensino do Exército, conforme previsto na Lei $n^{\circ}$ 9786, de 8 de fevereiro de 1999 (Lei de Ensino do

Exército).

A composição do corpo docente do CMPA/RS é relacionada da seguinte forma:

a) professores civis; b) professores militares; c) professores militares PTTC. Independentemente da categoria na qual o professor(a) pertence, está regimentado que este dará no máximo 15 tempos semanais de aula se no mesmo ano escolar. Caso os professores tenham dois anos escolares diferentes para ministrar aula, por exemplo, $7^{\circ}$ ano e $9^{\circ}$ ano, neste caso, é indicado que tenha apenas 10 tempos semanais de aula.

Assim, os profissionais docentes se envolvem em outros projetos e no caso dos militares, realizam tarefas relacionadas ao EB. 
Abaixo, apresento dois gráficos acerca da formação dos professores do CMPA/RS, neles temos os percentuais relacionados à formação continuada dos professores do Colégio Militar de Porto Alegre.

É perceptível que a maior parte dos professores possui mestrado e doutorado e que a formação continuada dos professores e a valorização dos mesmos, podem ser fatores que contribuem significativamente para os altos índices de qualidade na aprendizagem apresentados pelos alunos do CMPA (Colégio Militar de Porto Alegre).
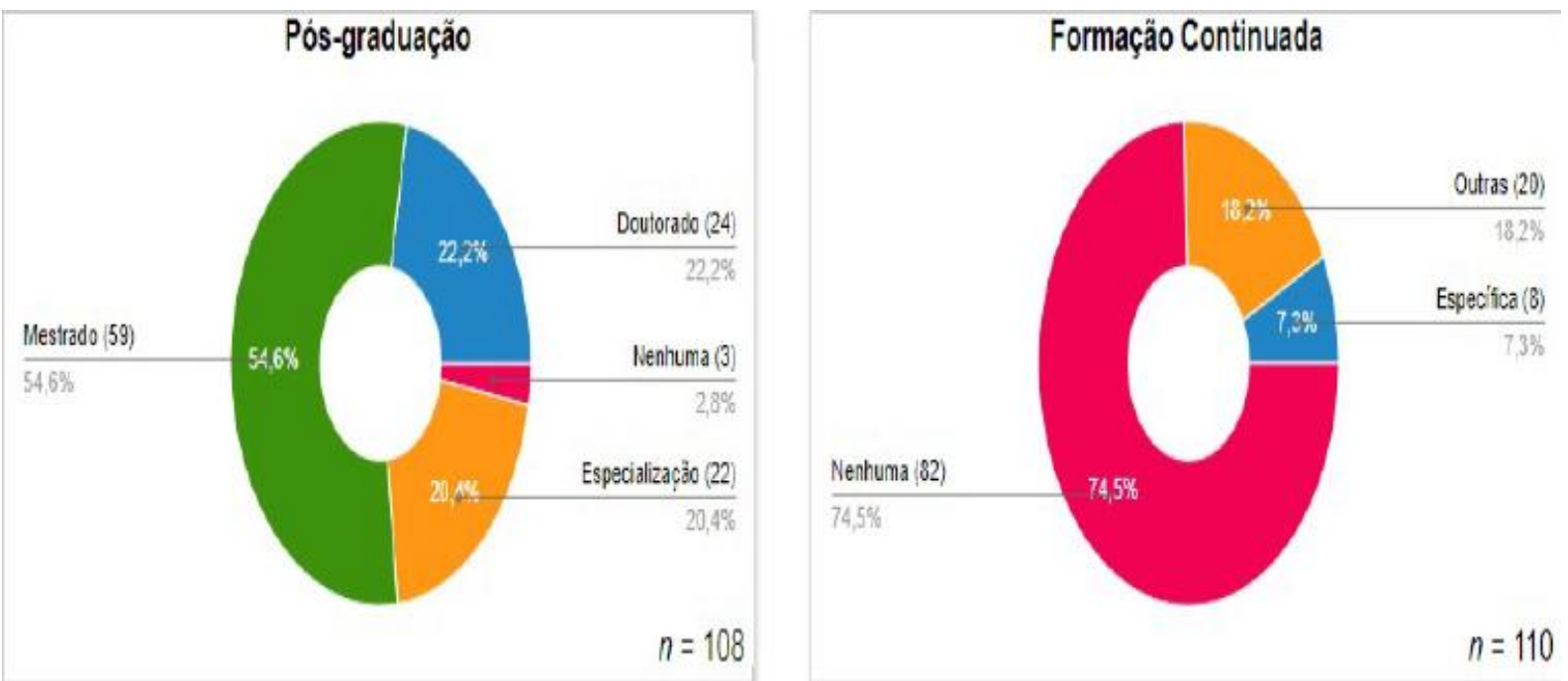

Figura 1 - Formação dos professores do CMPA

Fonte: Disponível em: <www.cultiveduca.ufrgs.br>. Acesso em 10 de agosto de 2018.

Fica claro que, apenas um percentual mínimo de profissionais não possui ensino superior completo, esse pequeno número corresponde aos militares coroneis da reserva (PTTC) que cursaram a AMAN (Academia Militar das Agulhas Negras), e que desta forma, até o ano de 2017 puderam atuar apenas com esta formação. Atualmente tal percentual não existe mais, pois conforme o previsto, tais militares deveriam cursar o ensino superior até o início de 2018 ou seriam retirados da sala de aula.

A formação continuada dos professores, evidentemente, é um grande diferencial nos espaços educacionais, e reflete diretamente na qualidade dos processos de ensino e de aprendizagem, para tal, destaco:

“[...] um dos programas prioritários em que estou profundamente empenhado é o de formação permanente dos educadores, por entender que os educadores necessitam de uma prática político-pedagógica séria e competente que responda à nova fisionomia da escola que se busca construir." (FREIRE, 2001, p. 80).

Conforme a reflexão acima supracitada, há necessidade de que os professores sejam oportunizados a realizar formações de forma permanente. Assim, tendo em vista a realidade 
na qual os professores do CMPA estão inseridos, além da formação que já possuem ao ingressar no SCMB, há a preocupação e o estímulo para que os mesmos continuem se qualificando, tais estímulos, estão relacionados as condições de trabalho e de carga horária, as dispensas para realizar a formação desejada e ao reconhecimento financeiro.

Desta forma, os processos de ensino e de aprendizagem do CMPA tornam-se de qualidade contribuindo assim, para o bom desempenho dos alunos.

\subsection{A realidade da Escola Pública do Município de Jaguarão.}

Neste momento trataremos do tema formação continuada com dados primeiramente da cidade de Jaguarão e logo após da escola especifica, material de análise desta pesquisa. Abaixo apresentamos os gráficos retirados do site de pesquisa CultvEduca da Universidade Federal do Rio Grande do Sul relacionados aos índices de professores que apresentam formação continuada no município.
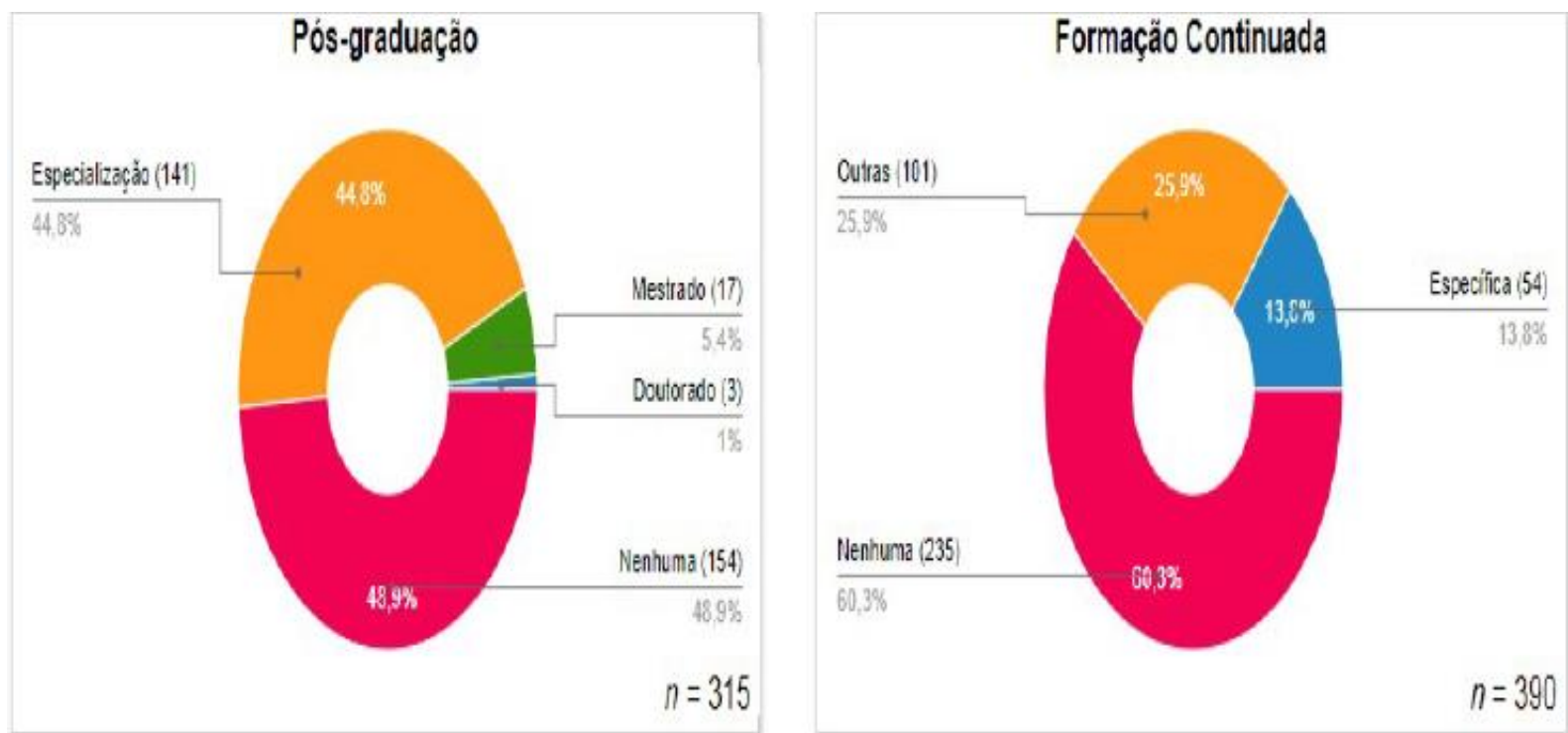

Figura 2 - Professores com formação continuada no município de Jaguarão/RS.

Fonte: Disponível em: 〈www.cultiveduca.ufrgs.br〉. Acesso em 10 de agosto de 2018.

Quando observamos o gráfico referente à formação continuada podemos observar que a maioria dos professores não possui formação continuada, o que nos leva a diversos caminhos e discussões acerca dos motivos que cercam estes dados estáticos, como por exemplo, a desvalorização salarial, a desmotivação, carga excessiva de trabalho dentre outros. No livro Formação Profissional Docente, Imbernón (2011) aborda algumas questões e problemáticas relacionadas ao desinteresse e estagnação profissional dos professores, dentre elas estão à falta de um debate sobre a formação inicial dos professores, a falta de 
coordenação, avaliação e acompanhamento dos responsáveis pelas formações, a improvisação nas modalidades destas, horários inadequados dentro outros fatores que contribuem com este elevado índice.

No que diz respeito à escola, a Escola Municipal de Ensino fundamental Marcílio Dias, os dados apresentados são:
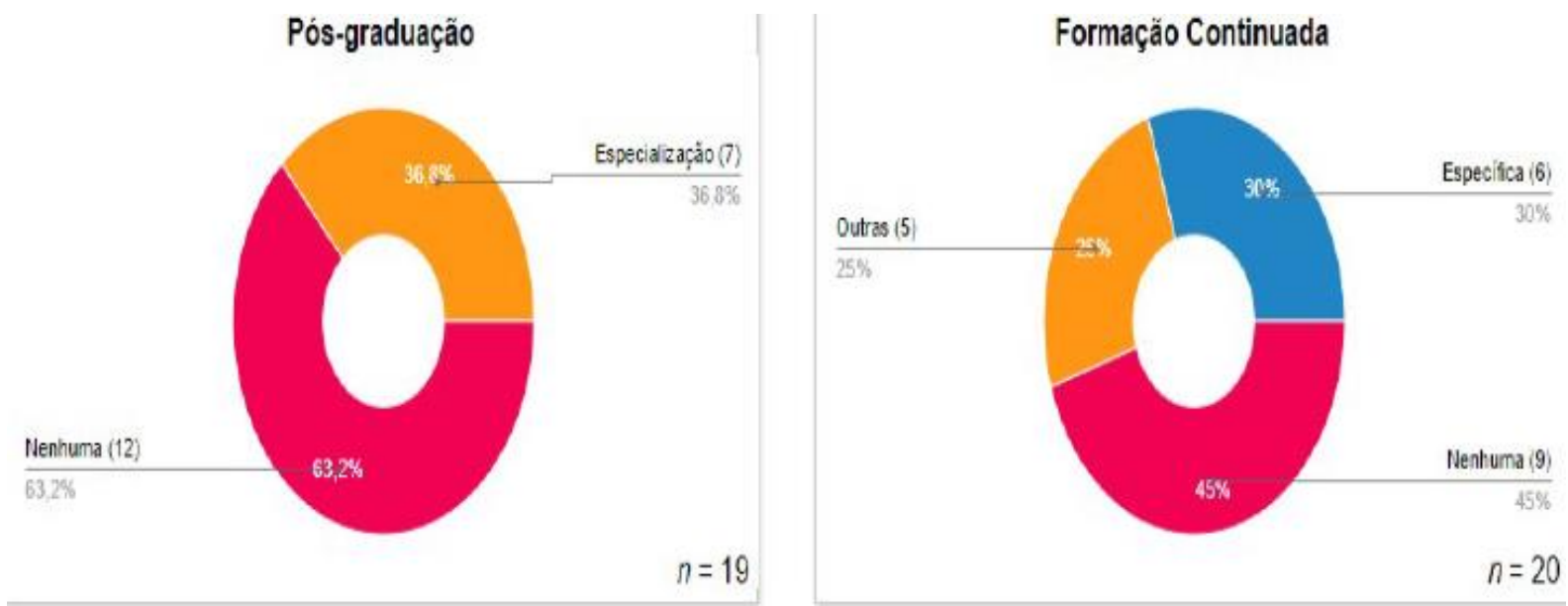

Figura 3 - Formação dos professores da EMEF Marcílio Dias.

Fonte: Disponível em: <www.cultiveduca.ufrgs.br>. Acesso em 10 de agosto de 2018.

Os dados apresentados nos gráficos referentes aos professores com Formação continuada na minha escola revelam um número considerável de profissionais que não apresentam Formação Continuada, um total de $45 \%$ dos profissionais atuantes na escola.

Segundo Imbernón (2011) os professores sentem-se mais seguros em trilhar caminhos mais conhecidos, como quando estão voltados a família ou métodos e trabalhos convencionais e com menos riscos, e quando tratamos sobre a Formação continuada, estes acabam por iniciar um percurso desconhecido e cheio de incertezas que ocasiona no medo do novo permanecendo com práticas pouco inovadoras.

Esta realidade abordada pelos autores, Nóvoa (2013) e Imbernón (2011) de fato encontro no meu ambiente de trabalho, profissionais que preferem a segurança de antigos métodos ou planejamentos ultrapassados ao invés de procurar por novos desafios ou práticas desafiadoras, permanecendo no que lhes dá maior segurança no cotidiano da sala de aula.

Outra questão abordada de suma importância nesta discussão, e que observo enquanto educadora e parte do processo, esta no planejamento dos temas abordados nas formações, que na grande maioria das vezes não esta de encontro as necessidades dos profissionais da 
educação, que sentem-se deslocados com as abordagens fora do seu contexto de trabalho. Para o autor,

\begin{abstract}
Os processos de formação devem analisar esses elementos desqualificadores para, a partir dos próprios grupos de professores, estabelecer mecanismos reajustes profissional, para que suas atuações não se limitem apenas as classes e às escolas, já que a profissionalização e o desenvolvimento profissional do grupo estão vinculados também a causas trabalhistas e sociais que devem ser enfrentadas em diversos foros. É necessária uma redefinição coletiva da profissão, de suas funções e de sua formação. (IBERNÓN, 2011, p.114)
\end{abstract}

Os dados apresentados contribuem para que possamos repensar os motivos de termos indicies tão altos de professores que não priorizam a formação continuada e as renovações de suas práticas. Sem dúvidas esta é uma questão emergencial a ser discutida no ambiente escolar, devendo o professor ser o eixo principal das questões a serem discutidas, buscando alternativas que visem a melhora do trabalho docente e das questões que envolvem sua profissionalização.

\title{
3. Conclusão
}

Quando falamos em valorização do magistério estamos reivindicando de fato sermos vistos como profissional que preparou-se para tal e não como um apaixonado que vive o sonho de ensinar. Um dos caminhos para que de fato tenhamos a valorização almejada está na formação continuada, para que de fato se obtenha o desenvolvimento profissional necessário. Nóvoa (2013) aborda a questão da valorização do conhecimento docente, indo ao encontro de que é necessário que seja visto o papel do educador enquanto transformador do conhecimento e não apenas como mero reprodutor deste, em suas palavras Nóvoa (2013) destaca,

\footnotetext{
"Se não concebermos o ensino como uma atividade de transmissão de um conhecimento preexistente, então o ofício poderá aprender-se por exercitação prática. Mas criação que tem o conhecimento preexistente como matéria-prima, então faz sentido conceber modelos universitários de formação de professores. A procura de um conhecimento profissional, que não é mera aplicação pratica de qualquer teoria de qualquer teoria, mas que exige um esforço próprio de elaboração e reelaboração, está no âmago do trabalho docente". (Nóvoa, 2013, p.203)
}

No que tange a valorização do profissional e profissão docente, a formação continuada serve como base a qualificação e consequente valorização dos educadores.

O professor precisa compreender a sua importância dentro do processo da construção da carreira docente e encontrar ferramentas para que seja capaz de superar as inúmeras dificuldades enfrentadas diariamente.

O comparativo entre as duas escolas demonstra o quanto duas instituições públicas de ensino podem apresentar diferentes realidades, tanto na estrutura física, como principalmente em relação à formação continuada de seus professores. Esse paradigma fica mais evidenciado 
quando relacionamos a valorização profissional recebida por ambos os profissionais, como por exemplo, salarial e de carga horária,

Para que os profissionais da educação sintam-se preparados para lidar com os desafios da sala de aula contemporânea, é necessário investir em formações que realmente façam a diferença em sala de aula, ou seja, oportunizar aos professores formações significativas. Diante disso, permanecem as seguintes reflexões:

- Como é possível realizar formações pedagógicas que resultem de forma positiva em sala de aula sem a participação e a consulta aos professores?

- O governo tem real interesse em promover e/ou investir em políticas públicas educacionais de qualidade?

- Como o professor consegue lidar com os desafios e a diversidade da sala de aula, realizar um planejamento de qualidade e significativo para os alunos, participar de formações, realizar leituras para o seu crescimento e desenvolvimento pessoal e profissional, tendo que driblar os desafios financeiros da sua própria vida, necessitando trabalhar 40 ou 60 horas semanais?

A partir dos dados e discussões realizadas neste artigo percebemos a necessidade de reflexão dos professores e gestores acerca da própria prática pedagógica, conscientização e auto-reflexão sobre a importância do fazer pedagógico e da mudança de concepção sobre a educação e o papel do professor nos dias de hoje, ressaltando o quanto as disparidades apresentadas nas instituições afetam o fazer pedagógico dos profissionais da educação.

\section{Referências}

FREIRE, Paulo. Pedagogia da Autonomia.25. ed. Rio de Janeiro: Paz e Terra. 2001.

IMBERNÓN, Francisco. Formação docente e profissional. São Paulo: Cortez, 2011.

NÓVOA, Antônio. Nada substitui um professor. Por uma política nacional de formação de professores / organização Bernardete Angelina Gatti [et. al].-1 ed.-São Paulo: Editora Unesp, 2013.

Plataforma CultivEduca. Disponível em: cultiveduca.ufrgs.br. Acessado em 18 de Julho de 2018. 